\title{
Condicionantes do Papel Estruturador Regional dos Nós e Terminais do Sistema de Transportes
}

Carlos Eduardo Zahn

Sumário

A força do sistema de transportes e de seus pontos nodais e terminais na organização do espaço regional é condicionada à existência de polftica de desenvolvimento global voltada às regiốes e à formulaçäo de polltica setorial de transportes, áquela integrada, definindo prioridades e hierarquias entre modos de transportes.

Abstract

Transportation frame terminals and knots are components that flow directly into the regional space structuration. That is conditioned by existing a development politics, orienting governamental actions in regional scale,integrated to a sectorial transport politics, determining priorities and hierarchies between transportation ways.
Arquiteto, Professor Doutor da FAUUSP.

Extrafdo da Tese de Doutorado "Os nós a termit nais do Sistema de Transportes/Elementos Estruturadores do Espaço Regional - O Caso do Estado de Sao Paulo", malo 1990.

Orientador: Prof. Dr. Lauro Bastos Birkholz. 
A tese defendida afirma que os pontos nodais e terminais do sistema de transportes são elementos que influenciam e orientam a estruturação do espaço regional e local em que se implantam. Sua confirmação é condicionada à pré-existência de fatores que the dão sustentação e validade, considerados como hipóteses de trabalho e que são apresentados neste artigo.

A idéia que fundamenta essas hipóteses é que, para otimizar o desempenho desses nós e terminais é necessário estabelecer relaçōes hierárquicas e funcionais entre os diversos modos de transporte. Para permitir que essas relações sejam claras, é necessária, também, a existência de uma polftica regional de desenvolvimento que oriente as decisōes quanto ao sistema de transportes.

Para conduzir o leitor à questão de interesse central, são feitas, a seguir, consideraçōes sobre a relevância da questão, expondo-se as hipóteses sob o ponto de vista dos condicionantes assumidos e dando um destaque à estrutura essencial do sistema de transportes, que se relaciona aos condicionantes pressupostos.

\section{Relevância da Questão}

A temática abrangida na tese refere-se a uma questāo aparentemente evidente, qual seja a influência do sistema de transportes, mediante seus pontos nodais e terminais, na estruturação do espaço em que se implantam tais equipamentos. Esta questão se reporta à outra, mais ampla, voltada à apreciação dos efeitos provocados pela implantação de equipamentos públicos em geral no meio ambiente e, em especial, na região e no espaço localizado sobre os quais se estende sua influência.

A análise destes problemas tem se mostrado cada vez mais justificável, pela complexidade das inter-relaçōes entre os diversos sistemas e redes de equipamentos públicos e, principalmente, pela intensidade das repercussões e impactos ambientais causados por sua implantação. As distorçōes, afetando o equilbrio ambiental urbano e regional, sucedem-se e acumulam-se de modo extremamente incisivo. As diversas formas de poluição bem como os desequilßbrios no sistema ecológico são, muitas vezes, provocados por decisōes errôneas quanto às polfticas de implantação de obras, equipamentos e serviços públicos, que passam a desservir à população à qual foram destinados.

Concomitantemente, a implantação racional de equipamentos públicos impöe-se, uma vez que os recursos para sua efetivação não são inesgotáveis e ilimitados, exigindo que se extraia maiores beneffcios com menores riscos, tendo em vista os custos sociais e financeiros de cada investimento governamental.

Para tanto, há que revalorizar o papel do processo de planejamento governamental em sua função ordenadora, principalmente em um contexto de escassez de recursos e de crescentes e prementes necessidades sociais e econômicas.

É desnecessário aprofundar-se na temática sócioeconômica envolvida na redução e racionalização dos gastos públicos: o tema é candente e atual. Suas causas e desdobramentos são abordados cotidianamente na imprensa e objeto de medidas governamentais freqüentes e, por vezes, desencontradas. Cabe lembrar somente que tais medidas, passando pela racionalização da máquina administrativa pública em todas as instâncias, desembocam obrigatoriamente na otimização dos investimentos governamentais, sem 0 que se tornariam inócuas. Somente por este rumo se obterá melhor objetividade de resultados frente ao desenvolvimento sócioeconômico da nação, de suas unidades federadas, das regiōes e das comunidades locais que a constituem.

Tal otimização passa necessariamente pela consciente e correta consideração do dimensionamento de obras e serviços, da redução da ociosidade das redes implantadas,

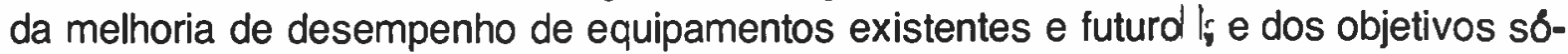
cioeconômicos do investimento público. Nessa conjuntura, que exige decisōes emergentes, os procedimentos de planejamento se redirecionam e seu processo assume novo papel, mais dinâmico e voltado ao gerenciamento da tomada de decisões. 
Os planos estruturais formulados nos anos 70 tiveram sua significação, principalmente enquanto sistematizadores de conhecimentos e interpretaçőes sobre as realidades sociais, económicas e territoriais. Entretanto, reduzida influência exerceram no processo de tomada das decisōes estratégicas de desenvolvimento, principalmente considerando o âmbito mais imediato das opçōes de implantação de investimentos públicos. A realidade mostrou que as alternativas suscitadas geralmente se colocaram bastante alêm da viabilidade económico-financeira de realização. Os entraves institucionais à adoção das medidas previstas se mostraram, também, freqüentemente insuperáveis pela tradição setorialista da administração pública e pela falta de visão integrada da ação, dos diversos niveis governamentais.

Hoje, o processo de planejamento busca critérios objetivos para direcionar as tomadas de decisões, a partir de diretrizes essenciais de desenvolvimento que permitam aos diversos niveis de decisão definir critérios para a implantação de equipamentos, aferir a objetividade dos investimentos previstos e avaliar seus niveis de desempenho.

Considerando essas premissas, amplia-se o papel do planejamento regional, enquanto instância de ligaçăo entre diretrizes globais e medidas concretas e pontuais de alcance local. Nessa escala permite-se uma visão mais integrada das conjunturas e condicionantes que regem problemas e limitam soluçōes de âmbito local. De outra parte, as diretrizes globais assumem maior concreção quando examinadas no contexto real da regiăo.

Especialmente no setor transporte, a visão regionalizada é fundamental. Do correto direcionamento de seus investimentos, podem advir beneffcios para o desenvolvimento integrado da regiāo, com efeitos multiplicadores no incremento industrial, na produção rural, nas atividades urbanas e na promoção das condiçōes de vida das populaçōes. Os pontos nodais e terminais do sistema de transportes, elementos de acesso ao sistema e de permeabilidade na conjugação dos seus meios, são fundamentais para promover e equilibrar as atividades regionais em seu conjunto. Essä̆ rede de nós e terminais permite a acessibilidade entre centros urbanos e áreas de produção, nas regiōes, inter-relacionando-os no âmbito intra-regional e com seus entornos externos.

\section{Condicionantes Assumidos}

Afirmar que os pontos nodais e terminais de um sistema de transportes podem se constituir em elementos estruturadores do espaço, orientando o desenvolvimento regional e local, só tem razão supondo que a implantação dessa rede de equipamentos obedeça a orientaçōes de carăter mais global, quanto a principios e diretrizes para esse desenvolvimento regional, sob o ponto de vista econômico e social e também quanto ao próprio sistema estruturado de transportes.

\section{Polltica Regional de Desenvolvimento}

As orientações assumidas frente ao desenvolvimento regional, transcendendo o mero elenco de regras operacionais, constituem-se no que se pode denominar de uma política. Tal polftica age como definidora de conjuntos de objetivos, de princlípios e de normas que orientam planos e programas de ação governamental ${ }^{1}$. Pode se referir a diversos âmbitos de ação, correspondendo a diferentes escalas de intervenção, desde a global até a local. Deve ainda especificar principios e normas que, dentro de um âmbito global, contemplem as peculiaridades da situação de cada porção do território, na ótica de um enfoque regionalizado. Assim, a premissa de existência de uma polltica orientadora do desenvolvimento, condicionando a ação governamental, refere-se especialmente à escala regional, agregadora entre princlipios norteadores para o desenvolvimento global nacional e normas de ação governamental local.

$\mathrm{Na}$ realidade brasileira, a questão regional não tem tido o destaque que aqui lhe é reservado. Os planos nacionais aprofundaram-se pouco nas peculiaridades regionais que as diretrizes de desenvolvimento deveriam assumir, em vista de diferenciaçōes da rea-
(1) Ver, sobre o concelto de polftica goverrie mental: RONCA, José Lulz C. A Interaçáo Entre o Urbano e o Rural no Brasil: Fator de Desenvolvimento Nacional. FAUUSP, Săo Paulo, 1981. (Cap. II. Item 2.2 p. 51) 
lidade em cada uma das regiões. No âmbito do estado de São Paulo, o enfoque regional do planejamento e da polftica de desenvolvimento se fez sentir por ocasiāo da formulação da "Polltica de Desenvolvimento Urbano e Regional", que traduziu princípios de desenvolvimento global, em termos de organização do espaço ${ }^{2}$. Nessa formulação definiu-se um conjunto integrado de medidas relacionando expectativas de desenvolvimento para o Estado a grandes objetivos nacionais e estabelecendo estratégias de intervenção sobre o espaço regional, compreendendo relações inter-urbanas da rede de cidades e deficiências dos sistemas intra-urbanos. Entretanto, esse esforço de planejamento regional teve reflexos pouco acentuados no sistema decisório e, conseqüentemente, pequena repercussão na ação setorial dos diversos agentes de governo.

Apesar dessas dificuldades mantém-se válido o princípio da necessidade de uma polftica de desenvolvimento que oriente a tomada de decisōes governamentais, principalmente em vista dos novos condicionantes econômico-sociais deste inf́cio de década de 90, quando à aparente abundância de recursos sucede-se à clara consciência de sua limitação e da necessidade de sua criteriosa aplicação.

Na polftica regional, é marcante a importåncia do setor transporte, parcela importante da ação governamental, com investimento público significativo, quer pelos montantes de recursos envolvidos, como pela extensāo e diversidade dos equipamentos que abrange. Além disso, o transporte tem repercussões diretas sobre os fatores de desenvolvimento econômico e social em qualquer âmbito pois seus meios e recursos permitem integração do território e escoamento de produção, bem como mobilidade social da população. Na escala regional, sua influência é marcante como fator de desenvolvimento rural e industrial, possibilitando acesso de insumos, escoamento de produtos às áreas consumidoras e mobilidade da mão-de-obra. No contexto urbano, o transporte tem papel relevante como fator de indução ao crescimento, favorecendo o adensamento populacional e a localização de atividades.

Sintetizando, conclui-se que a existência de uma polftica regional claramente estabelecida, orientando a tomada de decisões governamentais, ainda que de forma não explfcita, é condição indispensável para a racionalização de investimentos públicos. No transporte, esta polftica regional tem papel ainda mais relevante, pelas múltiplas repercussões que este setor apresenta sobre as atividades econômicas e sociais da região e das comunidades locais que a constituem.

\section{Polttica do Setor Transporte}

Para melhor contribuição das ações e investimentos em transportes à polltica global, é fundamental que os objetivos e princípios dessas ações sejam tambêm formulados constituindo uma polftica própria desse setor, normatizando e racionalizando programas e execução de investimentos.

Ordenar o setor transporte significa, antes de tudo, assumir a existência de relações hierárquicas e funcionais entre os seus meios. Essas relações não devem decorrer da situação dos sistemas e equipamentos disponlveis mas, em uma polftica de objetivos, estabelecer metas diferenciadas para a priorização de uso dos modos de transporte, em vista da diversidade de suas funções voltadas ao desenvolvimento econômico e social, na nação, na regiẫo e no meio urbano (Fromm, 1974). No caso do estado de São Paulo, com um sistema de transportes bastante desenvolvido, esta priorização implica, primordialmente, o aclaramento de relações internas no setor, que definam hierarquias de objetivos de ação.

É fundamental reconceituar as bases do sistema: a distribuição de funçōes entre os meios e a priorização de investimentos para os vários modos de transportes. Essa reconceituação permitirá a revalorização do modo ferroviário e a viabilização do hidroviário, frente à prevalência atual do modo rodoviário.

Esse reposicionamento entre meios de transporte permitirá a integração intermodal, conn significativa economia de investimento e com substancial incremento de eficiência nos serviços. Por isso é necessária a existência da polftica no setor, orientando prioridades de ação, com investimentos que revalorizem os diferentes meios, em vista de suas potencialidades de participação. 
A polttica de transporte, assim entendida, é pré-requisito ao equacionamento deste setor na polltica regional e, portanto, condicionante à efetivação do papel estruturador dos seus nós e equipamentos terminais no espaço regional e local.

\section{Estrutura Essencial para o Transporte}

Aceita a influência dos fatores condicionantes acima analisados, cabe analisar as bases da estrutura do setor transporte, integradamente a esses condicionantes. Os principais aspectos dessa estrutura, situando o transporte como suporte básico para uma polftica regional e definindo sua organização em rede de nós e terminais, são expostos a seguir.

Transporte: Suporte Básico da Polttica Regional

Supondo os investimentos em transporte equacionados de acordo com uma polftica própria do setor, integrada à polftica global, definem-se diversos fatores que contribuem diretamente à consecução de objetivos gerais de desenvolvimento econômico e social, particularmente no âmbito regional.

Deve-se ressalvar que o papel desempenhado pelo transporte não tem eficácia absoluta, mas necessita ser entendido no conjunto das diretrizes de desenvolvimento que abrangem outros setores, relacionados, por exemplo, ao incentivo económico, à oferta de bens, à disponibilidade de serviços públicos sociais. Mesmo nesses setores, 0 transporte poderá exercer influências decisivas sobre o dimensionamento e a localização de equipamentos, dependendo do dèsempenho de seus fatores, sucintamente elencados a seguir. (Fromm, 1974)

A - Acessibilidades: 0 transporte influencia significativamente toda a estrutura de acessibilidade no âmbito regional e local. Contribui profundamente para as possibilidades de desenvolvimento econômico à medida que abre frentes de localização para atividades produtivas, no setor primário e secundário, ampliando territórios com viabilidade de assentamento e estendendo a retroterra de apoio ou de mercado para a produção. Contribui também ao desenvolvimento econômico urbano, no setor terciário, permitindo mobilidade da população aos centros de serviços e influenciando o papel polarizador das cidades.

B - Escoamento de Produção: relacionado à acessibilidade, encontra-se o fator de escoamento de produção, também profundamente influenciado pelas facilidades de transporte. Beneficiando as condições de escoamento, no âmbito rural, passam a ser dinamizadas as condições de desenvolvimento sócioeconômico de amplas regiōes, pela sua melhor inserção e participação no sistema produtivo regional, permitindo a melhoria da qualidade de vida da população, integrando-a ao sistema econômico e possibilitando melhor distribuição de renda. Na localização industrial, a melhoria das condiçōes de escoamento possibilita ampliação dos fatores favoráveis a essa localização, com meIhor equilbrio regional dessa atividade, viabilizando desconcentração e regionalização da indústria.

C - Fixação e Mobilidade Populacional: a oferta de melhores condiçōes de transporte atua diretamente na mobilidade da população regional e de suas comunidades, o que se reflete primeiramente na escala local, no âmbito dos deslocamentos urbano-rurais, permitindo ao habitante rural o acesso aos beneffcios urbanos, à cultura e à participação social. Na escala intra-regional, a mobilidade contribui ao crescimento da qualidade de vida, ampliando relaçōes entre comunidades e possibilitando o surgimento de consciência regional. Permite também maior relacionamento inter-regional, ampliando 0 acesso aos recursos regionalmente distribuidos. Conseqüentemente, pode-se desenvolver expectativa de fixação populacional em seu meio, à medida que são facilitadas condiçōes de acesso aos beneffcios sociais oferecidos na própria região.

D - Relações Intra e Inter-regionais: em decorrência das interferências entre os fatores acima, o transporte influencia sensivelmente a própria estrutura de relaçōes da rede de cidades da regiāo e das regiōes próximas. Os graus de polarização exercidos pelos 


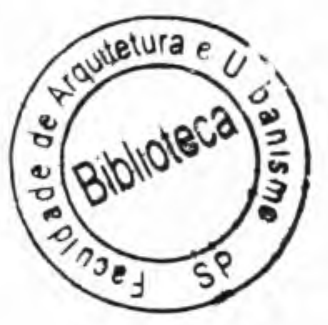

(3) Consideramrse modos de transporte: rodoviasrio, ferroviário, hidroviárío, aeroviárlo e de dutos.

(4) Relembrar que o falor transporte nâo pode ser considerado isoladamente como de efelto absoluto, particularmente no caso de promoção de áreas estagnadas ou não desenvolvidas, onde o transporte é apenas um dos quesitos Infra-estruturals necessários à reversåa do processo de subdesenvolvimento.

núcleos urbanos se alteram à medida que as facilidades de transporte se modificam, pela implantação de novas vias de acesso, de equipamentos geradores de fluxos, interferindo nos graus de desenvolvimento das atividades locais. Há diversos exemplos, tanto de núcleos e regiões que passaram a ter novo impulso de desenvolvimento regional, a partir de facilidades de transporte como também de áreas que se estagnaram pelo deslocamento dessas mesmas facilidades para outras regiōes.

\section{Organizaçāo do Sistema de Transportes}

O sistema de transportes, formulado a partir de uma polftica, tende a assumir uma organização que se caracteriza pela conjugação entre seus meios e pela forma de rede que esses meios desenvolvem na implantação territorial de suas vias e equipamentos (Faulks, 1973). A superposiçāo dos equipamentos dos diversos modos que integram esse sistema ${ }^{3}$ leva à sua organização geral, privilegiando os pontos de intersecção entre vias e aqueles onde se constituam feixes de meios e onde se localizem equipamentos de transferência entre eles. Esta tendência espontânea de organização pode ser reforçada e orientada caso a polftica de transporte considere e confirme as caracteIfsticas de malha do sistema, acoplando pontos de intersecção, equipamentos de transferência e áreas de concentração de diferentes meios.

E esses conceitos baseiam a hipótese que o sistema de transportes, para melhor contribuição à polftica de desenvolvimento regional, deverá se organizar através de rede de nós e terminais, canalizando facilidades e beneffcios do sistema, de acordo com as realidades e potencialidades regionais.

Considera-se um nó a porção do espaço onde se aglutinam diferentes facilidades do sistema de transportes, de um ou mais meios, e onde se permite a conjugação entre essas facilidades e sua interface com outros equipamentos correlacionados ao transporte: áreas de armazenagem, silagem, processamento de mercadorias.

O terminal é o equipamento onde se processa o destino final de um determinado meio de transporte, de cargas ou de passageiros, podendo ser conjugado entre diferentes modos, constituindo-se em um dos elementos integrantes de um nó de transporte.

A implantação de equipamentos terminais de transportes gera, para a localidade em que se instala, uma multiplicidade de fatores de desenvolvimento, favorecendo sobremaneira essa localidade no contexto regional. Caso esse equipamento se constitua em um nó de inter-relação entre diferentes modos de transporte, seu papel polarizador se intensifica, abrangendo áreas de influência tanto mais amplas quanto mais desenvolvida a função desse nó.

A força exercida pelos nós e terminais pode produzir repercussões sensiveis sobre a estrutura de organização regional e local, tornando necessário considerar sua localização integradamente às diretrizes gerais de ordenamento nessas escalas. No âmbito regional, surgem alteraçōes de polarização entre núcleos urbanos, influindo nos ritmos e fluxos de evolução, produzindo efeitos multiplicadores de tendências econômicas, ou induzindo efeitos corretivos, de redirecionamento, evitando saturação de espaços congestionados e promovendo desenvolvimento de áreas estagnadas ${ }^{4}$. Em åmbito local, a implantação de nós e terminais produz a aceleração de indicadores de desenvolvimento urbano, pelos fatores de acessibilidade e mobilidade. Sua presença poderá modificar tendências de localização de atividades e de população e produzindo novas necessidades de acesso local, de equipamentos e de infra-estrutura.

\section{Referências Bibliográficas}

FROMM, Gary. La Inversion en el Transporte y el Desarrolo Económico. Bueno Alres: Troquel, 1974.

- Op. cito - Capltulos 5 a 8.

FAULKS, R. W. Principles of Transport. London: Ian Allan, 1973. 